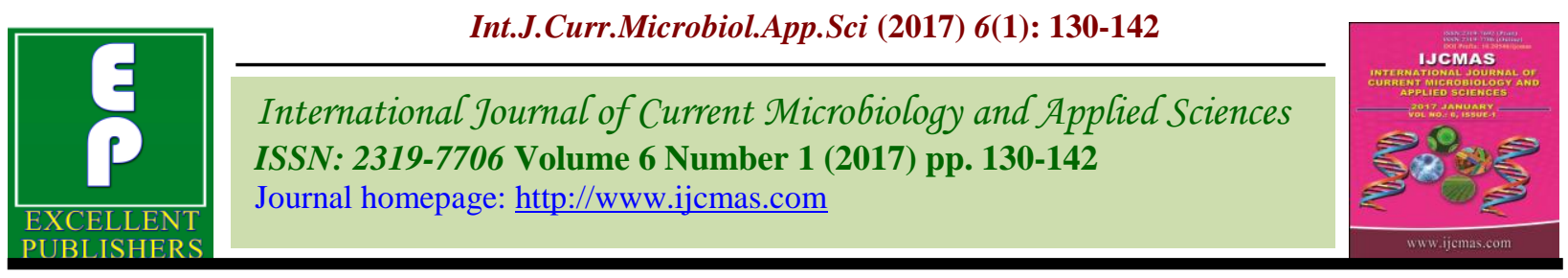

Original Research Article

http://dx.doi.org/10.20546/ijcmas.2017.601.017

\title{
Application of Dental Implants Coated with Titanium Nitride: The Experimental Study with Porphyromonas gingivalis Infection
}

\author{
Koutaro Yamazaki ${ }^{1}$, Izumi Mashima ${ }^{2,3,4}$, Futoshi Nakazawa ${ }^{3}$, \\ Yasuhiro Nakanishi ${ }^{1}$ and Morio Ochi ${ }^{1}$ *
}
${ }^{1}$ Division of Fixed Prosthodontics and Oral Implantology, Department of Oral Rehabilitation, School of Dentistry, Health Sciences University of Hokkaido, Hokkaido, Japan
${ }^{2}$ Postdoctoral Fellow of Japan Society for the Promotion of Science, Tokyo, Japan
${ }^{3}$ Department of Oral Microbiology, School of dentistry, Health Sciences University of Hokkaido, Hokkaido, Japan
${ }^{4}$ Department of Oral Biology, School of Dental Medicine, University at Buffalo, The State University of New York, New York, USA.
*Corresponding author

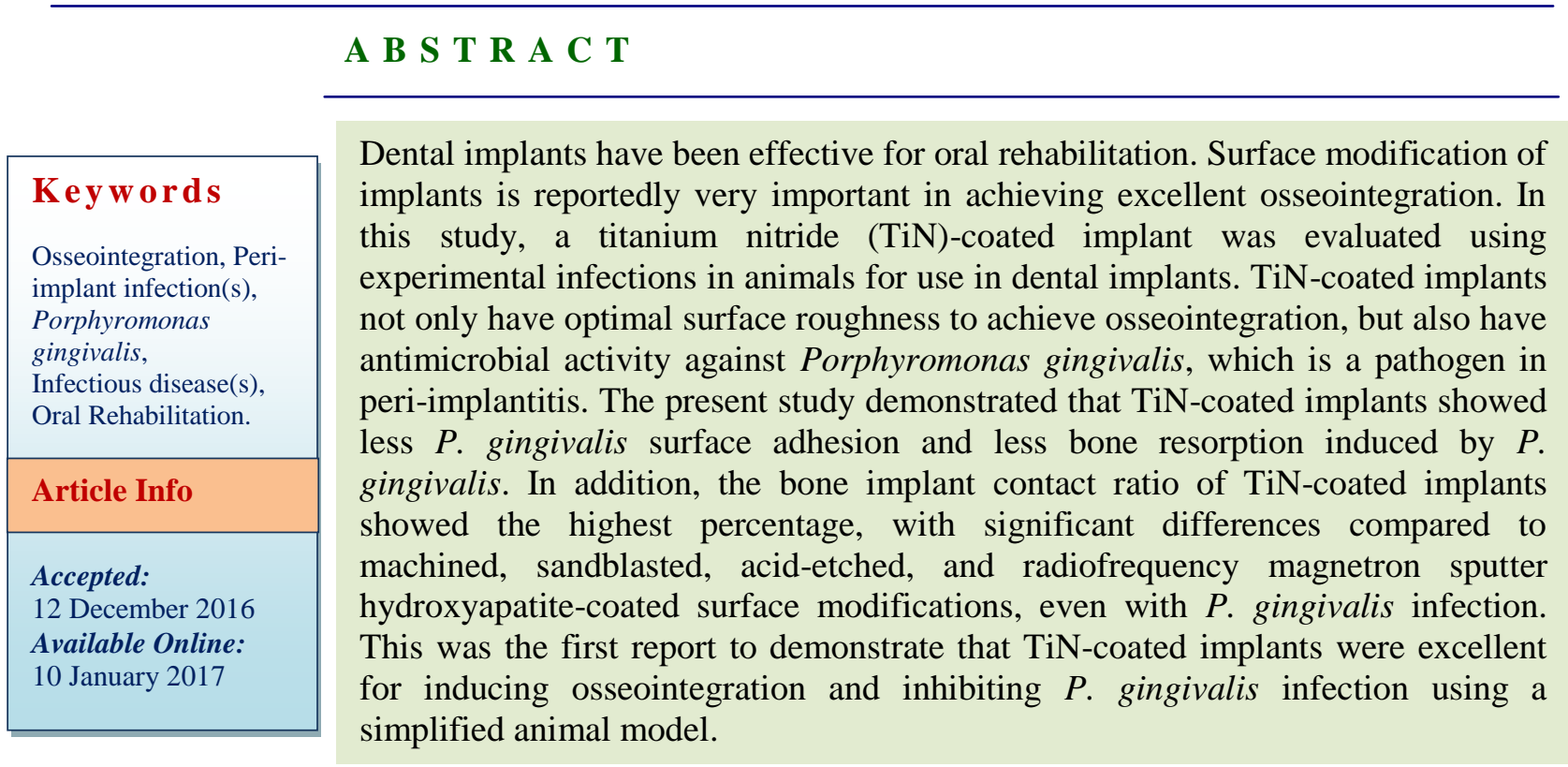

\section{Introduction}

The most common dental implant material is commercially-pure (cp) titanium. In recent years, modifications have been made to machined titanium implants with the aim of optimizing osseointegration (Lazzeara et al., 1999; Lang et al., 2009). These modifications to increase the speed and success of osseointegration have included hydroxyapatite coatings, increasing surface roughness and surface free energy (Yoshinari et al., 2002). Increasing surface roughness has been achieved with a titanium plasma-sprayed (TPS) surface, sand blasting, acid etching, and a sand-blasted large-grit acid-etched surface 
(SLA) (Schroeder et al., 1996). However, the amounts of bacterial adhesion and oral biofilm accumulation were reportedly accelerated by increasing surface roughness (Amoroso et al., 2006; Teughels et al., 2006). It was also difficult to remove these bacteria from the implant surface (Albouy et al., 2010). Bacterial adhesion to biomaterials is an important factor in the pathogenesis of infection. Peri-implantitis is a common complication in implant therapy and is characterized by inflammatory lesions in periimplant tissues and associated loss of supporting bone (Zitzmann and Berglundh, 2008). It is by definition an infectious disease and the inflammatory lesion in peri-implant tissues develops as a result of accumulation of bacteria on implant surfaces. Some studies reported that peri-implantitis occurs in $28 \%$ to $56 \%$ of subjects and at $12 \%$ to $43 \%$ of implant sites (Ferreira et al., 2006; RoosJansaker et al., 2006). The surface roughness and chemical composition of the implant surface are important in bacterial adhesion.

Titanium nitride $(\mathrm{TiN})$ is a ceramic with great hardness $\left(2,000 \mathrm{~kg} / \mathrm{mm}^{2}\right)$, high decomposition temperature $\left(2,949^{\circ} \mathrm{C}\right)$, defect structure, i.e., deviation from stoichiometry, chemical stability at room temperature, superconductivity, and gold-yellow color (Toth 1971). TiN is mainly used as a coating to enhance other materials. TiN shows encouraging blood tolerability properties with hemolysis percentage near zero (Dion et al., 1992). Therefore, TiN-coatings are used in cardiology for ventricular assist devices in patients with heart failure (Sin et al., 2009) and for pacemaker leads (Schaldach et al., 1989). In neurology, TiN-coated electrodes are used in chronically implanted devices for the treatment of spinal cord injury (Cogan, 2008). TiN-coating is also used in orthopedic implants, because of its excellent biological properties, such as the reduction of the release of cobalt-chromium-molybdenum ions, and the aesthetic appeal of the "golden color" (Mezger and Creugers, 1992; Wisbey et al., 1987).

It is important to consider $\mathrm{TiN}$ for use in implants because of reports about periimplantitis. However, the utility of $\mathrm{TiN}-$ coated cp titanium dental implants using an experimental infection model has not been investigated in vivo. This study evaluated biological response in bone 2 weeks after placement of TiN-coated cp titanium implants using Porphyromonas gingivalis, a pathogen in peri-implantitis (Mombelli, 1997), in a simplified rabbit model.

\section{Materials and Methods}

\section{Animals}

This study was approved by the Animal Ethics and Research Committee of Health Sciences University of Hokkaido, Hokkaido, Japan (Approval No. 72). All animal experiments complied with the Guidelines for the Care and Use of Laboratory Animals of the University. A total 20 adult male Japanese white rabbits weighing approximately $2.5 \mathrm{~kg}$ (Hokudo Co, Sapporo, Japan) were used in this study. The rabbits were kept under a 24hour light/dark cycle and had free access to drinking water at the Animal Experiment Center.

\section{Dental Implants}

Forty threaded $\mu$-One HA implants (Yamahachi Dental MFG., Co., Aichi, Japan) ( $\varphi 3.3 \mathrm{~mm}$, length $10.0 \mathrm{~mm}$, identical in size to those in clinical use) were machined from a cp titanium rod (JIS TYPE 2) for use in this study. They were divided into 4 different groups based on surface modification: implant type M, machined; B, sandblasted and acidetched; HA, radiofrequency magnetron sputter hydroxyapatite (HA)-coated (1-2 $\mu \mathrm{m})$; 
TiN, TiN-coated $(3.1 \mu \mathrm{m})$ using an arc ion plating system (AIP-S40, KOBELCO, Tokyo, Japan) for $90 \mathrm{~min}, 150 \mathrm{~A}, 30 \mathrm{~V}$, with $\mathrm{N}_{2}$ partial pressure of $4 \mathrm{~Pa}$.

\section{Surface Topography and Roughness}

Scanning electron microscopy (SEM) (SSX550, Shimazu, Japan) was used for an overall picture of the surface topography of implants with each surface modification. SEM micrographs were taken at the surface between the $2^{\text {nd }}$ and $3^{\text {rd }}$ threads of the implant at a magnification of $1,000 \times$.

Quantitative characterization of the surface topography and roughness was carried out by 3-dimensional (3D) laser microscopy (LEXT OLS4000, Olympus, Tokyo). The roughness (Ra) of each implant was determined to set the $\mathrm{X}$ and $\mathrm{Y}$ horizontal and vertical axes of the implants. One sample of each preparation type was analyzed at randomly chosen areas $\left(258 \times 258 \mu \mathrm{m}^{2}\right.$, cutoff value: $\left.8 \mu \mathrm{m}\right)$ on the flat part at the bottom of the implant.

\section{Bacterial Strain and Culture Conditions}

P. gingivalis ATCC $33277^{\mathrm{T}}$ and Prevotella intermedia ATCC $25611^{\mathrm{T}}$ were used in this study. Culture was on Bacto ${ }^{\mathrm{TM}}$ Brain Heart Infusion (BHI, Difco Laboratories, BD) supplemented with 5\% (volume/volume) defibrinated sheep blood (BHI agar), hemin $(10 \mu \mathrm{g} / \mathrm{mL})$, and menadione $(5 \mu \mathrm{g} / \mathrm{mL})$ under anaerobic conditions $\left(\mathrm{N}_{2}: \mathrm{CO}_{2}: \mathrm{H}_{2}=\right.$ $80 \%: 10 \%: 10 \%)$ at $37^{\circ} \mathrm{C}$ for 5 days. Bacterial cells of $P$. gingivalis colonies were collected with a cotton wool stick, washed, and suspended in phosphate-buffered saline (PBS) $(\mathrm{pH} 7.2)$ to a turbidity equivalent to $\mathrm{OD}_{660}=$ $10.0\left(1.5 \times 10^{9}\right.$ cells $\left./ \mathrm{mL}\right)$, and also suspended in BHI broth supplemented with hemin and menadione to a turbidity equivalent to $\mathrm{OD}_{660}$ $=0.1\left(1.5 \times 10^{7}\right.$ cells $\left./ \mathrm{mL}\right)$ with $\mathrm{a}$ spectrophotometer.

\section{Bacterial Adherence Test}

Bacterial adherence to the M-, B-, HA-, and TiN-coated disks, $\varphi 10 \mathrm{~mm}$, thickness $1 \mathrm{~mm}$, was examined for $P$. gingivalis. Each of the 4 kinds of disks were placed in a 24-well plate and incubated with $1 \mathrm{~mL}$ of bacterial suspension in BHI broth $\left(\mathrm{OD}_{660}=0.1\right)$ for 2 weeks under anaerobic conditions at $37^{\circ} \mathrm{C}$. Medium replacements were carried out every 5 days in 2 weeks. After incubation, the disks were transferred to $1 \mathrm{~mL}$ PBS and vortexed for $2 \mathrm{~min}$ to roughly remove bacterial cells from the disk surface. The disks were then transferred to $1 \mathrm{~mL}$ PBS again and sonicated for $30 \mathrm{~s}$ to completely remove the bacterial cells. After the disks were removed, the PBScontaining bacterial cells were mixed and centrifuged $\left(8,500 \mathrm{rpm}, 4^{\circ} \mathrm{C}, 15 \mathrm{~min}\right)$. The precipitated bacterial cells were suspended to $1 \mathrm{~mL}$ with PBS.

A $100-\mu \mathrm{L}$ suspension was transferred to 900 $\mu \mathrm{L}$ of PBS, and serially diluted 10 -fold with sterile saline from $10^{-3}$ to $10^{-7}$. A $100-\mu \mathrm{L}$ aliquot of diluted solution was placed on $\mathrm{BHI}$ blood agar plates, spread evenly with beads, and cultured for 5 days under anaerobic conditions at $37^{\circ} \mathrm{C}$. After incubation, colonyforming units (CFU) were counted.

The entire genomic DNA was extracted by InstaGene Matrix Kit (Bio-Rad) according to the manufacturer's instructions from the residual $900 \mu \mathrm{L}$ of the precipitated bacterial cell suspension to measure the total amount of bacteria. DNA concentrations were determined by measuring absorption at $\mathrm{OD}_{260}$. The results were analyzed from 3 independent experiments performed in triplicate.

\section{Surgical Procedure and $P$. gingivalis Provision}

Dental implant placement was performed under general anesthesia using intravenous 
pentobarbital sodium $\quad 16.2 \quad \mathrm{mg} / \mathrm{kg}$ (Somnopentyl Kyoritsu seiyaku Co., Tokyo, Japan) into the ear vein. After preparing the surgical field, local anesthesia was performed using lidocaine $\mathrm{HCl}$ containing $2 \%$ epinephrine $1.8 \mathrm{mg} / \mathrm{kg}$ (Xylestesin A injection solution, ESPE, Germany). The procedure of implant placement was previously described (Nakanishi et al., 2011).

After implant placement, silk threads were twisted 4 times on the abutment-implant junction. $P$. gingivalis suspension $15 \mu \mathrm{l}$ $\left(\mathrm{OD}_{660}=10.0\right)$ was applied to silk threads on the left side as the infection model, P. $g(+)$; $15 \mu \mathrm{l}$ of PBS was applied to the silk threads on the right side as the control, $P . g(-)$. Then, one eco-tube $(4 \times 6 \mathrm{~mm})$ and one silicone tube $(5 \times 7 \mathrm{~mm})$ were used to prevent the silk threads from falling out, followed by suturing of the periosteum and skin. No antimicrobial agents were used. The experiments were repeated 5 times for each type of implant $(\mathrm{M}$, $\mathrm{HA}, \mathrm{B}$, and TiN). The experimental period lasted for 2 weeks, as in a previous report (Ochi et al., 2003).

\section{Bacterial Sampling}

After the rabbit was sacrificed with a pentobarbital sodium overdose, bacterial samples were collected using sterile paper points (ISO \#35) from the sulcus around the implant. Samples were also collected from the control side. The samples were immediately placed in $1 \mathrm{~mL}$ of sterile PBS, vortexed for 2 min, and homogenized 100 times to disperse bacterial cells from the paper points. The bacterial cells from the paper points were collected by centrifugation.

DNA Extraction and Detection of $P$. gingivalis by Polymerase Chain Reaction (PCR)

Genomic DNA was extracted from individual samples using the InstaGene Matrix Kit. DNA concentrations were determined by measuring absorption at $\mathrm{OD}_{260}$.

For detection of all bacteria, a 16S rDNA universal primer set (forward: 5'GAGAGTTTGATYMTGGCTCAG-3', reverse: 5'-GAAGGAGGTGWTCCARCCG CA-3') (Paster et al. 2001) was used. A specific primer set (forward: 5'-AGGCAGC TTGCCATACTGCG-3, reverse: 5'-ACTG T TAGCAACTACCGATGT-3') (Bogen and Slots 1999) was also used to detect $P$. gingivalis. PCR was performed according to previous reports (Paster et al., 2001; Bogen and Slots, 1999).

$P$. intermedia, which is genetically related to $P$. gingivalis, was used as a negative control. PCR products were applied to $1.5 \%$ agarose gels. Following electrophoresis, gels were stained with $\mathrm{SYBR}^{\circledR}$ Safe DNA gel stain (Invirogen).

\section{Sample Removal and Specimen Preparation}

After bacterial sampling, surrounding bone including the implant in both sides of the femurs was removed. The specimen preparation procedure was previously described by Nakanishi et al., (2011).

\section{Observation by Contact Microradiography (CMR) and Measurement of Bone Implant Contact Ratio (BIC)}

Pictures of samples with a thickness of 120 $\mu \mathrm{m}$ were taken using a soft X-ray generation device (Sofron Model BSTI 1505CX ${ }^{\circledR}$ Souken Laboratory, Tokyo, Japan). Bone resorption area $\left(\mathrm{mm}^{2}\right)$, bone resorption depth $(\mathrm{mm})$, and maximum bone resorption width $(\mathrm{mm})$ around the implant were measured after magnification correction, shown in Fig. 1(a).

BIC was measured by using sections stained with basic fuchsin and methylene blue. 
Measurements were separately conducted for upside BIC (from the top of the implant to the $3^{\text {rd }}$ thread) and downside BIC (from the $4^{\text {th }}$ thread to the bottom of the implant). Computer analysis with NIH Image ${ }^{\circledR} 1.61$ (National Institutes of Health, Bethesda, MD, USA) was performed with image analysis software. BIC was calculated as the ratio of the contact length of the implant and newlyformed bone adjacent to the implant as peripheral length (contact length/implant peripheral length of implant and newly formed bone) $\times 100 \%$.

\section{Statistical Analysis}

Statistical significance was determined using Tukey's analysis after one-way analysis of variance (ANOVA) with SPSS $^{\circledR}$ Statistics 22 (IBM SPSS Inc., Chicago, IL, USA). A pvalue of $<0.05$ was considered statistically significant.

\section{Results and Discussion}

\section{Laboratory Animals}

No anomalous variation or abnormal findings in rabbits infected with $P$. gingivalis were observed for the 2 weeks of the experiment.

After 2 weeks, inflammation in the affected area was observed in all $P . g(+)$ groups. Specifically, tumefaction and reddening in all P. $g(+)$ groups, and drainage in $P . g(+) \mathrm{HA}$ and B groups, were observed. No inflammation in the affected area was detected in any of the $P . g(-)$ groups (data not shown).

\section{Surface Topography and Roughness}

The surface topography of M-, B-, HA-, and TiN-coated implants is shown in Fig. 2(a) SEM images. $M$ had the typical topography of machined samples: flat and smooth, with machining grooves. B, HA, and TiN had many surface concavities and convexities, but no drastic vertical interval in the 3D laser microscopy image, Fig. 2(b). The surface roughness $(\mathrm{Ra})$ was calculated according to the 3D laser microscopy image. The results of $\mathrm{Ra}$ (X axis, Y axis) ( $\mu \mathrm{m})$ were shown in Table 1. According to the $\mathrm{Ra}$ measurement, $\mathrm{M}$ clearly showed less roughness than B, HA, and TiN. Furthermore, HA showed less roughness than $\mathrm{B}$ and $\mathrm{TiN}$.

\section{Bacterial Adherence Test}

The amount of bacterial adherence to the M-, B-, HA-, and TiN-coated disks was determined by $\mathrm{CFU}$ and the total amount of DNA. The mean $\mathrm{CFU}$ values $(\mathrm{CFU} / \mathrm{mL})$ and the amounts of DNA (ng) were shown in Table 1 . These data indicated that cells of $P$. gingivalis did not tend to adhere to $\mathrm{TiN}$, but the results showed no significant difference.

\section{Detection of $P$. gingivalis}

No PCR products were detected in any $P . g$ (-)-affected areas by analysis using the $16 \mathrm{~S}$ rDNA universal primer set. PCR products were confirmed in all but the $P . g(+)$-affected TiN areas using the same primer set (data not shown).

The results of PCR analysis with the specific primer set for $P$. gingivalis are shown in Fig. 3. This analysis demonstrated that $P$. intermedia could not manufacture PCR products with the specific primers (Fig. 3, lane 2). This result indicated the specificity and utility of the specific primer set for $P$. gingivalis. PCR products were only confirmed in $P . g(+)$-affected areas of M, B, and HA (Fig. 3, lanes 3, 4, and 6). However, there were fewer PCR products from $P . g(+)$ affected areas of $\mathrm{M}$ than those of $\mathrm{B}$ and HA. No PCR products were confirmed in $P . g(+)-$ affected areas of $\mathrm{TiN}$, or in any $P . g(-)$ affected areas (Fig. 3, lanes 5, 7, 8, 9, and 10). 
CMR Images and Measurement of Bone Resorption Area, Depth, and Width around the Implant

CMR images of M, B, HA, and TiN with P. $g$ $(-)$ and $P . g(+)$ are shown in Fig. 1(b). In the upper stages, there was no visible bone resorption with any type of implant in $P . g(-)$ groups, but in lower stages, visible bone resorption was observed in B and HA of the P. $g(+)$ groups.

Bone resorption area $\left(\mathrm{mm}^{2}\right)$, bone resorption depth $(\mathrm{mm})$, and the maximum of bone resorption width $(\mathrm{mm})$ around the implant were measured in detail and shown in Table 1. In the $P . g(-)$ group, there were no significant differences.

In contrast, in the $P . g(+)$ group, there were significant differences between $\mathrm{HA}$ and $\mathrm{M}, \mathrm{B}$, and TiN as shown in Fig 1(c). In addition, the mean values of bone resorption depths and widths showed significant differences in both depths and widths between $\mathrm{M}$ and $\mathrm{HA}$, between $\mathrm{HA}$ and TiN, and between $\mathrm{M}$ and $\mathrm{B}$, shown in Fig. 1(d), (e).

\section{Histologic Observation and Measurement of BIC}

Fig. 4(a), (b) shows the results of images stained with basic fuchsin and methylene blue. Existing bone was pink with basic fuchsin and methylene blue dyes, and bonelike tissue was purplish-red. Although newlyformed immature bone stained purplish-red was observed for all types of implant surfaces, the amounts in the $P . g(+)$ group, shown in Fig. 4(b), were less than those in the P. $g(-)$ group, shown in Fig 4(a).

BIC (\%) was measured 2 weeks after the implant operation. The mean values of upside BIC in the $P . g(-)$ groups and $P . g(+)$ group were shown in Table 1 . There was a significant difference between TiN and M, B, and HA, shown in Fig. 4(c). The mean values of downside BIC in the $P . g(-)$ group and $P . g$ $(+)$ group were shown in Table 1 . There was a significant difference between $\mathrm{M}$ and $\mathrm{B}, \mathrm{HA}$, and TiN, shown in Fig. 4(d), (e).

A series of animal studies concluded that osseointegration can occur using an implant with a rough surface, but is difficult to achieve using a once-contaminated, machined (smooth) implant surface (Persson et al., 2001).

In this study, B and TiN showed greater surface roughness than $\mathrm{M}$ and HA, suggesting that TiN was suitable as an implant surface to achieve osseointegration. In other studies, some regions of the TiN-coated implants showed no bone opposition at 4 weeks, but after 24 weeks, some specimens showed direct bone opposition in dog femurs (Hayashi et al., 1989). The affinity of bone for the implant index of TiN-coated stainless steel was comparable to that of alumina, but not significantly better than uncoated stainless steel (Hayashi et al., 1989). TiN-coated Ti6Al4V rods were implanted in rat femurs and showed biocompatibility and bonebonding properties similar to uncoated Ti6Al4V rods (Sovak et al., 2000). Relative bone area and BIC of TiN-coated cp titanium threaded implants in rabbits were similar to $\mathrm{TiO}_{2}$-coated cp titanium (Larsson et al., 2013).

In this study, the amounts of bone resorption and BIC with $P$. gingivalis infection were evaluated by using 4 kinds of implant surfaces including TiN-coating. In the CMR images, HA in the $P . g(+)$ group showed high amounts of bone resorption, whereas $\mathrm{M}$ and TiN in the $P . g(+)$ group showed low resorption. Henry et al., (1994) reported that HA implants more easily caused bone resorption with peri-implantitis than titanium 
implants. On the other hand, M reportedly caused bone resorption less easily because the machined (smooth) surface made it difficult for $P$. gingivalis to adhere. In addition, PCR results showed that $P$. gingivalis was not detected on $\mathrm{TiN}$, and was detected less on $\mathrm{M}$ than on B and HA. However, in the bacterial adherence test results, only TiN did not show good adherence by $P$. gingivalis. Therefore, the results of our study partly support some reports (Henry et al., 1994; Persson et al., 2001), and suggest that the results of differences for $M$ occurred in the in vitro and in vivo studies because of totally different conditions.

Table.1 Summary of results in this study

\begin{tabular}{|c|c|c|c|c|c|c|c|c|c|c|c|c|c|c|}
\hline \multirow{3}{*}{\begin{tabular}{|c|} 
Surface \\
Modification
\end{tabular}} & \multirow{2}{*}{\multicolumn{2}{|c|}{$\begin{array}{c}\text { Surface Topography and Roughness } \\
\operatorname{Ra}(\mu \mathrm{m})\end{array}$}} & \multicolumn{2}{|c|}{ Bacterial Adherence Test } & \multicolumn{6}{|c|}{ Measurement from CMR Images } & \multicolumn{4}{|c|}{$B I C$} \\
\hline & & & \multirow{2}{*}{$\begin{array}{l}\text { CFU } \\
\text { (mL) }\end{array}$} & \multirow{2}{*}{$\begin{array}{l}\text { DNA } \\
(\mathrm{ng})\end{array}$} & \multicolumn{3}{|c|}{ P.g () } & \multicolumn{3}{|c|}{$P . g(t)$} & \multicolumn{2}{|c|}{ P.g $(-)[\%]$} & \multicolumn{2}{|c|}{$\operatorname{P.g}(+)[\%]$} \\
\hline & Xaxis & Yaxis & & & Bone resorption area [ $\left.\mathrm{mm}^{2}\right]$ & Depth [mm] & Widh $[\mathrm{mm}$ & 1] Bone resorption area $\left[\mathrm{mm}^{2}\right.$ & 2) Depth [mm & n] With $[\mathrm{mm}$. & |) Upside & Downside & Upside & Downside \\
\hline M & $0.024 \pm 0.005$ & $0.016 \pm 0.002$ & $1.02 E+08$ & 504.7 & 0.21 & 0.22 & 0.41 & 0.21 & 0.13 & 0.19 & 65.6 & 50.7 & 54.3 & 56.0 \\
\hline B & $0.207 \pm 0.018$ & $0.259 \pm 0.011$ & $976 E+07$ & 549.4 & 0.22 & 0.23 & 0.23 & 0.86 & 1.05 & 0.54 & 80.6 & 80.5 & 56.0 & 74.4 \\
\hline HA & $0.191 \pm 0.015$ & $0.202 \pm 0.019$ & $1.01 E+08$ & 575.7 & 0.10 & 0.20 & 0.21 & 1.68 & 1.33 & 0.80 & 78.8 & 83.5 & 53.8 & 76.9 \\
\hline TiN & $0.237 \pm 0.038$ & $0.269 \pm 0.028$ & $5.66 E+07$ & 445.7 & 0.13 & 0.42 & 0.21 & 0.36 & 0.57 & 0.36 & 77.1 & 75 & 77.3 & 70.1 \\
\hline
\end{tabular}

Fig 1a The results of measurement of bone resorption; blue: bone resorption area, red arrow: bone resorption depth, yellow arrow: bone resorption width

(a)
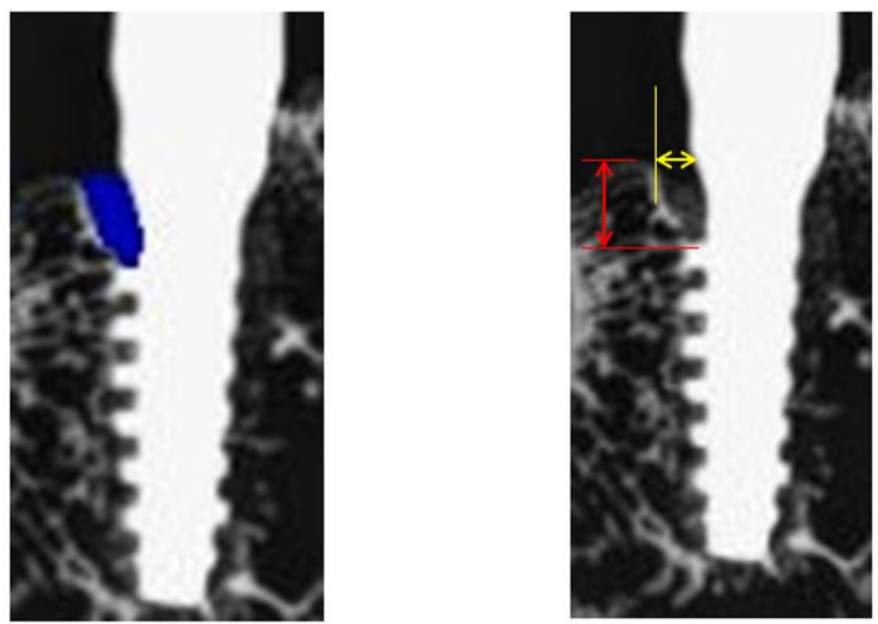
Fig 1b CMR images of M, B, HA, and TiN, with P. g (-) (upper stage) and P. g (+) (lower stage); red circles show visible bone resorption, (c): The results of measurement of bone resorption areas $(\mathrm{mm} 2),{ }^{*} \mathrm{P}<0.05,(\mathrm{~d})$ : The results of measurement of bone resorption depths $(\mathrm{mm}),{ }^{*} \mathrm{P}<$ 0.05 , (e): The results of measurement of bone resorption widths $(\mathrm{mm}), * \mathrm{P}<0.05$.

(b)
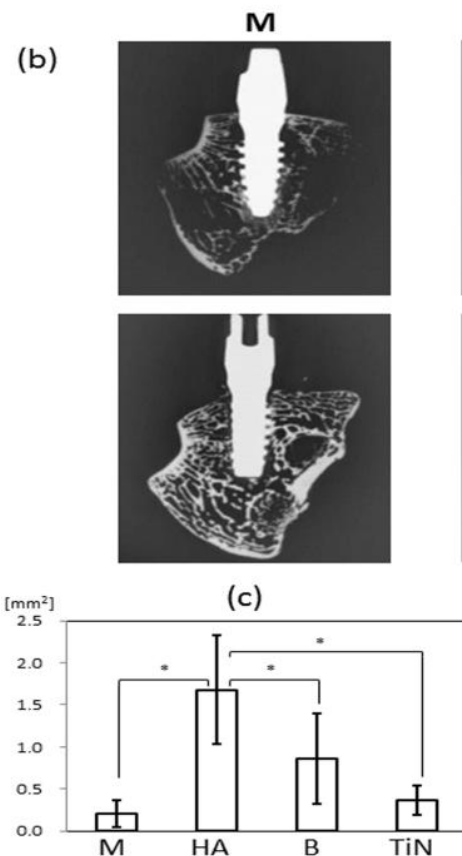

HA
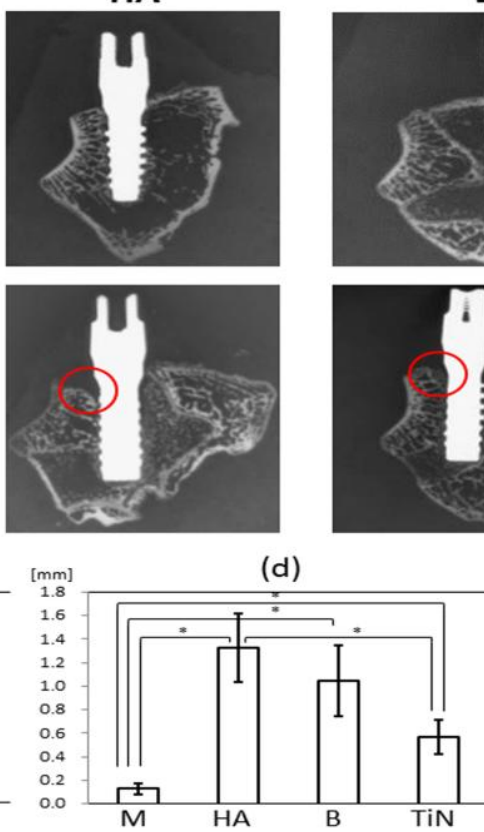

B
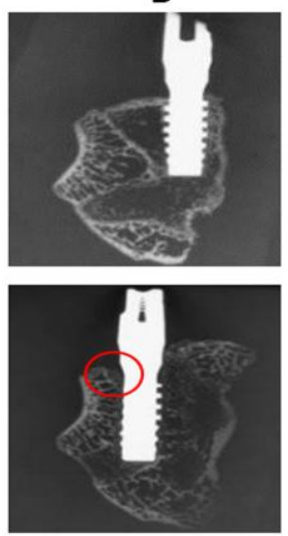

$[\mathrm{mm}]$
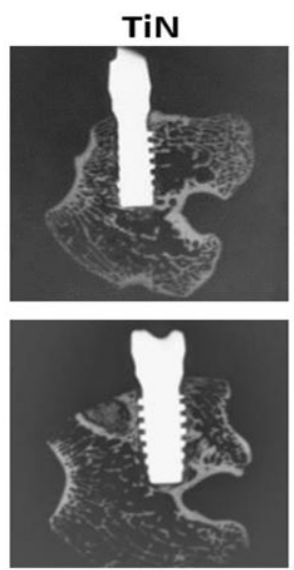

(e)

Fig 2a Scanning electron microscopy (SEM) images (1,000× magnification) of M, B, HA, and TiN, (b): 3D laser microscopy images (50× magnification) of M, B, HA, and TiN.

(a)

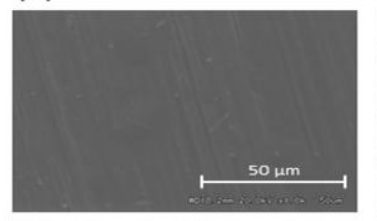

(b)

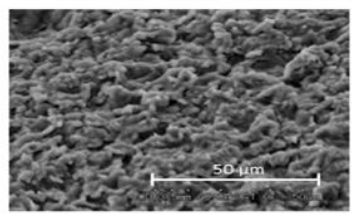

HA

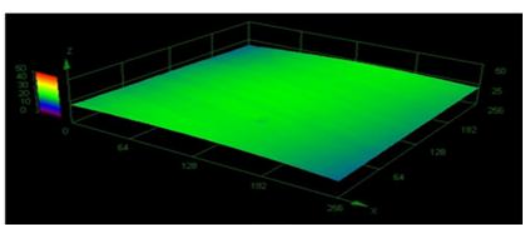

M

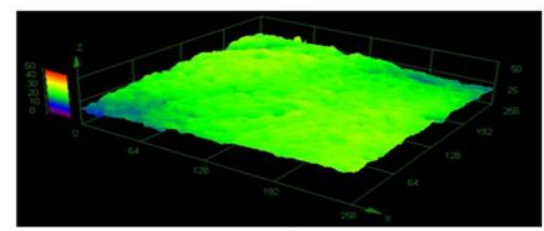

$\mathbf{B}$

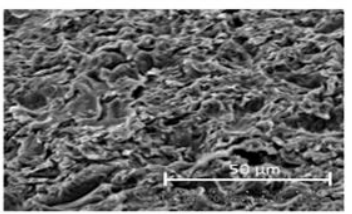

B

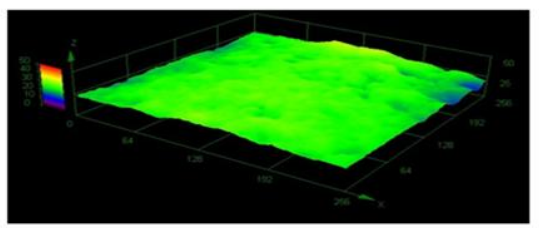

HA

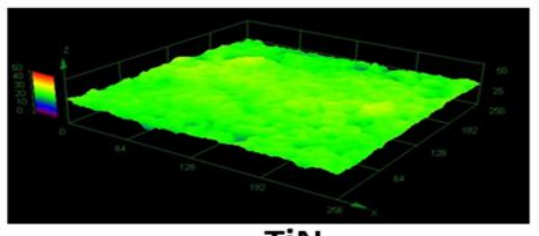

TiN 
Fig 3 The results of PCR electrophoresis with specific primer for P. gingivalis: lane 1, P. gingivalis ATCC 33277T as positive control; lane 2, P. intermedia ATCC 25611T; lane 3, HA in the P. $g(+)$ group; lane 4, B in the P. $g(+)$ group; lane 5, TiN in the P. $g(+)$ group; lane 6, M in the P. $g(+)$ group; lane 7, HA in the P. g (-) group; lane 8, B in the P. g (-) group; lane 9, TiN in the P. $g(-)$ group; lane 10, M in the P. $g(-)$ group.

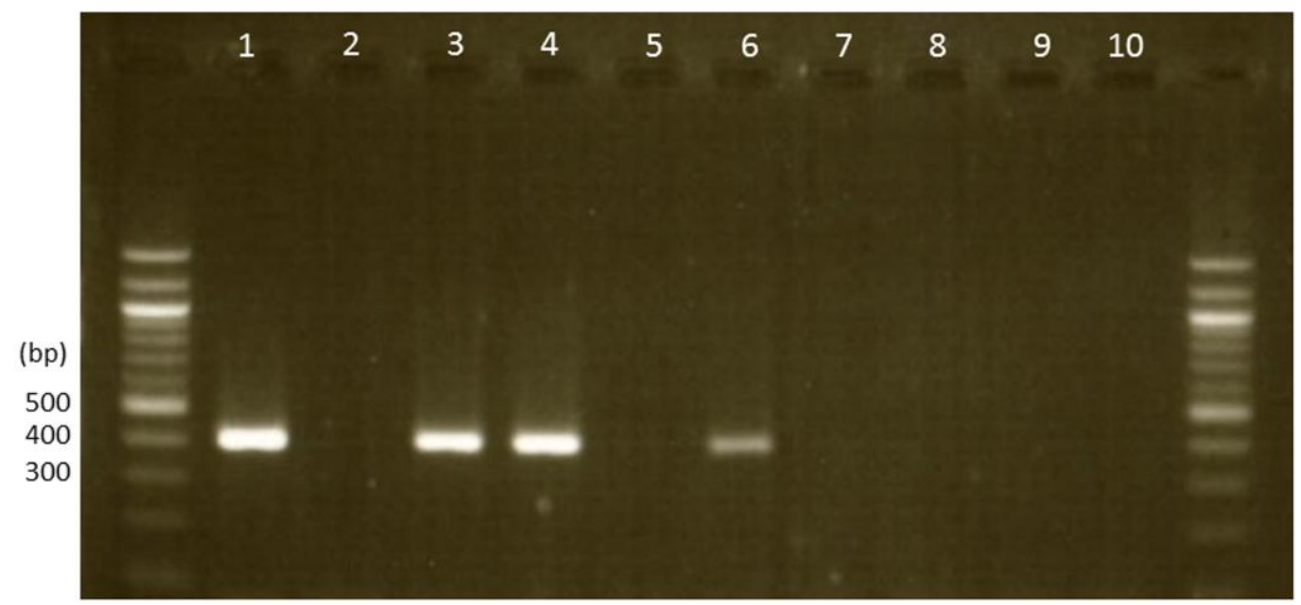

Fig 4a Images of M, B, HA, and TiN, with P. g (-) groups stained with basic fuchsin and methylene blue ( $7 \times$ and $15 \times$ magnification), (b): Images of M, B, HA, and TiN, with P. g (+) groups stained with basic fuchsin and methylene blue ( $7 \times$ and $15 \times$ magnification), (c): The results of measurement of upside BIC with $\mathrm{P} . \mathrm{g}(+),{ }^{*} \mathrm{P}<0.05$, (d): The results of measurement of downside BIC with P. g (-), *P $<0.05$, (e): The results of measurement of downside BIC with P. $g(+), * P<0.05$.

(a)
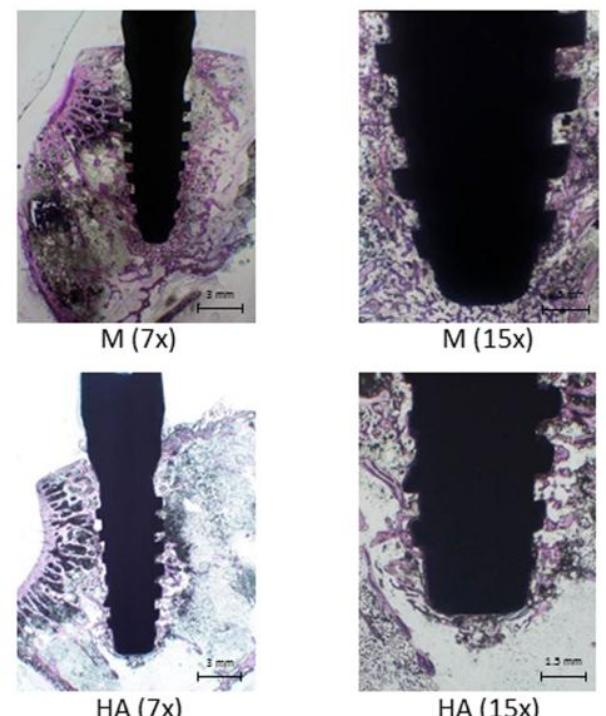

$\mathrm{M}(15 \mathrm{x})$

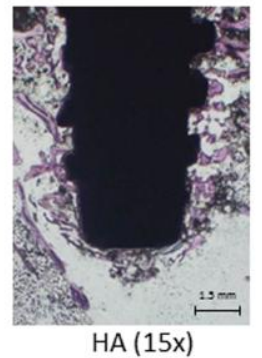

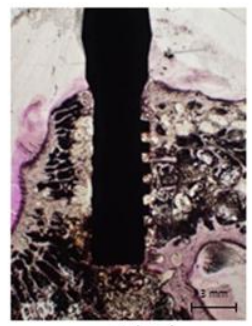

$\mathrm{B}(7 \mathrm{x})$

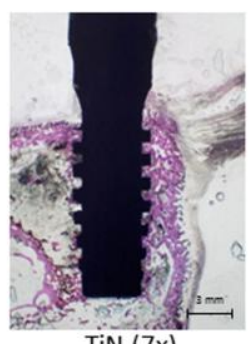

TiN (7x)

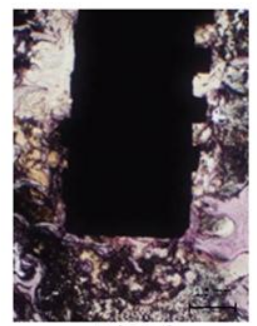

$B(15 x)$

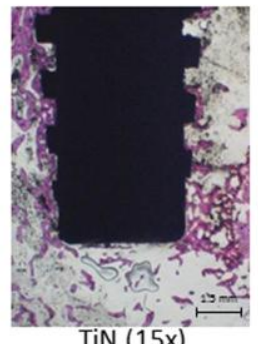


(b)
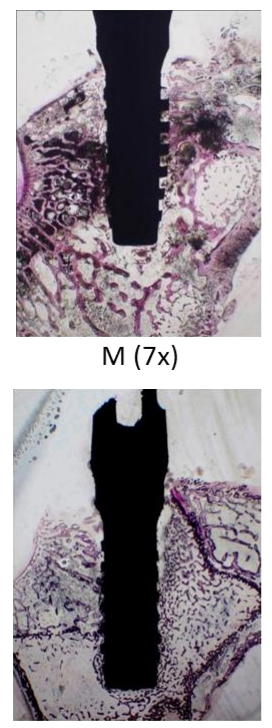

HA (7x)
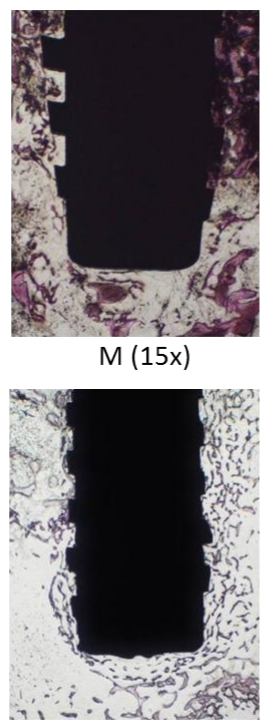

HA (15x)
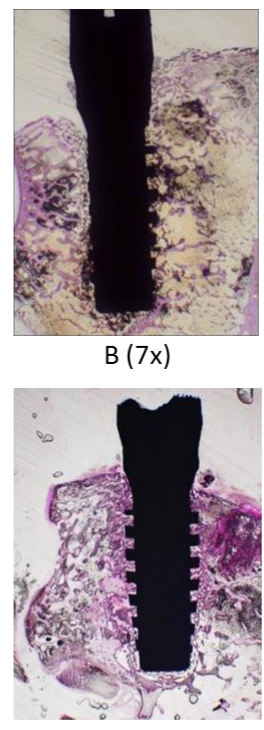

TiN (7x)

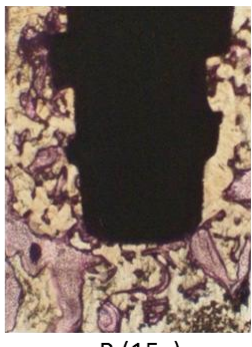

$B(15 x)$

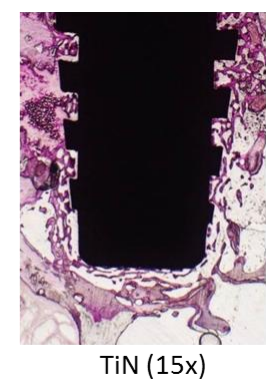

(c)

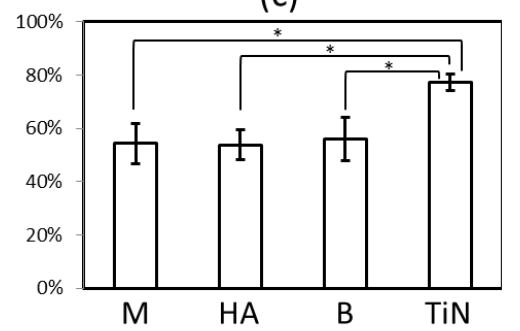

(d)

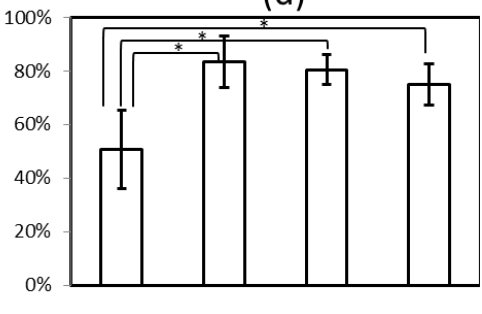

(e)

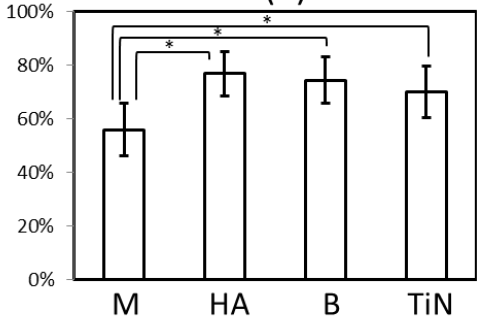

Despite the surface roughness of TiN, adherence by $P$. gingivalis was difficult. Annunziata et al., (2008) reported that results of three independent experiments showed lower adhesion and proliferation $(\mathrm{P}<0.05)$ by Streptococcus pyogenes and S. sanguinis on TiN-coated TPS surfaces. In addition, TiN surfaces showed a significant reduction of the presence of bacteria, which could be important in decreasing inflammation in periimplant soft tissues (Scarano et al., 2003). Furthermore, Ji et al., (2015) reported that their in vitro study evaluated antimicrobial activity against not only $S$. mutans but also $P$. gingivalis by TiN-coating on titanium. The results in this study confirmed that $\mathrm{TiN}$ exercised antimicrobial activity against $P$. gingivalis both in vivo and in vitro. The results of the upside BIC in the $P . g(+)$ group showed the highest percentage for TiN. It was suggested that TiN induced bone formation and inhibited $P$. gingivalis adhesion, thus preventing inflammation. Moreover, Ji et al., (2015) reported that TiN-coated titanium did not influence osteoblast-like cell viability. However, the downside BIC in the P. $g(+)$ group showed almost the same high percentage for B, HA, and TiN. Yuan et al., (2014) reported that BIC with $P$. intermedia infection showed a higher percentage in the implant with a smooth compared to a rough surface. This report conflicted with our results. However, Yuan et al., (2014) used implants completely dipped in bacterial suspension. Our study only used silk threads with a bacterial suspension to infect implants with $P$. gingivalis. The different infection methods may have resulted in different findings between our study and that of them. Furthermore, in the results for the upside BIC, there was only a significant difference between TiN and M, B, and HA. This might 
indicate that our experimental period of 2 weeks was sufficient to infect the upside implants. However, future studies using a longer experimental period are needed to evaluate infection of downside implants.

The present study was the first to report that TiN-coated cp titanium implants are excellent as dental implants to induce osseointegration and inhibit $P$. gingivalis infection using a simplified animal model. It is expected that TiN-coated cp titanium implants will be used as dental implants.

\section{Acknowledgements}

We are grateful to Dr. Hiroshi Miyakawa, the Department of Oral Microbiology, School of Dentistry, Health Sciences University of Hokkaido; Dr. Taro Andou of the dental training course, Health Sciences University of Hokkaido; Dr. Yukito Hirose, Dr. Yoko Kimura, Dr. Naoki Tamura, and Dr. Masayasu Akanuma, of the Division of Fixed Prosthodontics and Oral Implantology, Department of Oral Rehabilitation, School of Dentistry, Health Sciences University of Hokkaido; and Dr. Hiroaki Takebe, the Division of Histology, Department of Oral Growth and Development, for technical assistance. This study was supported in part by grants-in-aid from the Japan Society for the Promotion of Science (JSPS) Fellows (15J30007), Scientific Research from KAKENHI (grant 26462793), and the 20142015 Research Project of the Research Institute of Personalized Health Sciences, Health Sciences University of Hokkaido. The authors declare no conflicts of interest associated with this manuscript.

\section{References}

Albouy, J.P., Abrahamsson, I., Persson, L.G., Berglundh, T. 2011. Implant surface characteristics influence the outcome of treatment of peri-implantitis: an experimental study in dogs. J. Clin. Periodontol., 38(1):58-64.

Amoroso, P.F., Adams, R.J., Waters, M.G., Williams, D.W. 2006. Titanium surface modification and its effect on the adherence of Porphyromonas gingivalis: an in vitro study. Clin. Oral Implants Res., 17(6):633-637.

Annunziata, M., Oliva, A., Basile, M., Giordano, M., Mazzola, N., Rizzo, A., Lanza, A., Guida, L. 2011. The effects of titanium nitride-coating on the topographic and biological features of TPS implant surface. J. Dent., 39(11): 720-728.

Bogen, G., Slots, J. 1999. Black-pigmented anaerobic rods in closed periapical lesions. Int. Endodont. J., 32(3): 204210.

Cogan, S.F. 2008. Neural stimulation and recording electrodes. Annu. Rev. Biomed. Eng., 10: 275-309.

Dion, I., Baquey, C., Candelon, B., Monties, JR. 1992. Hemocompatibility of titanium nitride. Int. J. Artif. Organs, 15(10): 617-621.

Ferreira, S.D., Silva, G.L., Cortelli, J.R., Costa, J.E., Costa, F.O. 2006. Prevalence and risk variables for periimplant disease in Brazilian subjects. $J$. Clin. Periodontol., 33(12):929-935.

Hayashi, K., Matsuguchi, N., Uenoyama, K., Kanemaru, T., Sugioka, Y. 1989. Evaluation of metal implants coated with several types of ceramics as biomaterials. J. Biomed. Mater. Res., 23(11):1247-1259.

Henry, P., Johnson, B., Kirsch, A. 1994. Solutions for specific soft tissue situations. Int. J. Oral Maxillofac. Imp., 9E Suppl: 30-38.

Ji, M.K., Park, S.W., Lee, K., Kang, I.C., Yun, K.D., Kim, H.S., Lim, H.P. 2015. Evaluation of antibacterial activity and osteoblast-like cell viability of TiN, $\mathrm{ZrN}$ and $\left(\mathrm{Ti}_{1-\mathrm{x}} \mathrm{Zr}_{\mathrm{x}}\right) \mathrm{N}$ coating on titanium. $J$. 
Adv. Prothodont., 7:166-171.

Lang, N.P., Jepsen, S., Working Group 4. 2009. Implant surfaces and design (Working Group 4). Clin. Oral Implants Res., 20(Suppl 4):228-231.

Larsson, W.C., Thomsen, P., Aronsson, B.O., Tengvall, P., Rodahl, M., Lausmaa, J., Kasemo, B., Ericson, E.L. 2013. Bone response to surface-modified titanium implants: Studies on the early tissue response to implants with different surface characteristics. Int. J. Biomater., 2013:10 pages. Article ID: 412482.

Lazzara, R.J., Testori, T., Trisi, P., Porter, S.S., Weinstein, R.L. 1999. A human histologic analysis of osseotite and machined surfaces using implants with 2 opposing surfaces. Int. J. Periodontics. Restorative. Dent., 19(2): 117-129.

Mezger, P.R., Creugers, N.H. 1992. Titanium nitride coatings in clinical dentistry. $J$. Dent., 20(6):342-344.

Mombelli, A. 1997. Etiology, diagnosis, and treatment considerations in periimplantitis. Curr. Opin. Periodontol., 4:127-136.

Nakanishi, Y., Wang, L.P., Ochi, M., Nakanishi, K., Matsubara, H. 2011. Low-intensity Pulsed Ultrasound Stimulation Significantly Enhances the Promotion of Bone Formation Around Dental Implants. J. Hard. Tissue. Biol., 20(2):149-156.

Ochi, M., Wang, L.P., Ohura, K., Takashima, S., Kagami, H., Hirose, Y., Kaku, T. and Sakaguchi, K. 2003. Solcoceryl, a tissue respiration stimulating agent, significantly enhances the effect of capacitively coupled electric field on the promotion of bone formation around dental implants. Clin. Oral Implants Res., 14(3): 294-302.

Paster, B.J., Boches, S.K., Galvin, J.L., Ericson, R.E., Lau, C.N., Levanos, V.A., Sahasrabudhe, A., Dewhirst, FE.
2001. Bacterial diversity in human subgingival plaque. J. Bacteriol. 183(12):3770-3783.

Persson, L.G., Berglundh, T., Sennerby, L., Lindhe, A. 2001. Re-osseointegration after treatment of peri-implantitis at different implant surface - An experimental study in the dog. Clin. Oral Implants Res., 12(6):595-603.

Roos-Jansåker, A.M., Lindahl, C., Renvert, H., Renvert, S. 2006. Nine- to fourteenyear follow-up of implant treatment. Part II: presence of peri-implant lesions. J. Clin. Periodontol., 33(4):290-295.

Scarano, A., Piattelli, M., Vrespa, G., Caputi, S., Piattelli, A. 2003. Bacterial adhesion on titanium nitrade-coated and uncoated implants: An in vivo human study. $J$. Oral Implantol., 29(2): 80-85.

Schaldach, M., Hubmann, M., Hardt, R., Weikl, A. 1989. Titanium nitride cardiac pacemaker electrodes. Biomed. Tech. (Berl)., 34(7-8):185-190.

Schroeder, A., Sutter, F., Buser, D., Krekeler, G. eds. 1996. Oral Implantology. Basics, ITI Hollow Cylinder System. Georg Thieme Verlag, Stuttgart and Thieme Medical Publishers, Inc., New York.

Sin, D.C., Kei, H.L., Miao, X. 2009. Surface coatings for ventricular assist devices. Expert Rev. Med. Devices, 6(1):51-60.

Sovak, G., Weiss, A., Gotman, I. 2000. Osseointegration of Ti6Al4V alloy implants coated with titanium nitride by a new method. J. Bone Joint Surg. Series B., 82(2):290-296.

Teughels, W., Van, A.N, Sliepen, I., Quirynen, M. 2006. Effect of material characteristics and/or surface topography on biofilm development. Clin. Oral Implants Res., 17(Suppl 2):68-81.

Toth, L.E. 1971. Transition Metal Carbides and Nitrides. Academic Press, New York, NY, USA. 
Wisbey, A., Gregson, P.J., Tuke, M. 1987. Application of PVD TiN coating to CoCr-Mo based surgical implants. Biomaterials, 8(6):477-480.

Yoshinari, M., Oda, Y., Inoue, T., Shimono, M. 2002. Dry-Process Surface Modification for Titanium Dental Implants. Metall Mater Trans A., 33(3):511-519.

Yuan, K., Chan, Y.J., Kung, K.C., Lee, T.M.
2014. Comparison of osseointegration on various implant surfaces after bacterial contamination and cleaning: A rabbit study. Int. J, Oral. Maxillofac. Imp., 29(1):32-40.

Zitzmann, N.U., Berglundh, T. 2008. Definition and prevalence of periimplant diseases. J. Clin. Periodontol., 35(Suppl 8):286-291.

\section{How to cite this article:}

Koutaro Yamazaki, Izumi Mashima, Futoshi Nakazawa, Yasuhiro Nakanishi, Morio Ochi. 2017. Application of Dental Implants Coated with Titanium Nitride: The Experimental Study with Porphyromonas gingivalis Infection. Int.J.Curr.Microbiol.App.Sci. 6(1): 130-142. doi: http://dx.doi.org/10.20546/ijcmas.2017.601.017 